Copyright (C) 2016 by Academic Publishing House Researcher

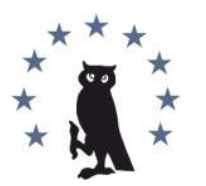

Published in the Russian Federation

European Researcher

Has been issued since 2010.

ISSN 2219-8229

E-ISSN 2224-0136

Vol. 107, Is. 6, pp. 324-329, 2016

DOI: 10.13187/er.2016.107.324

www.erjournal.ru

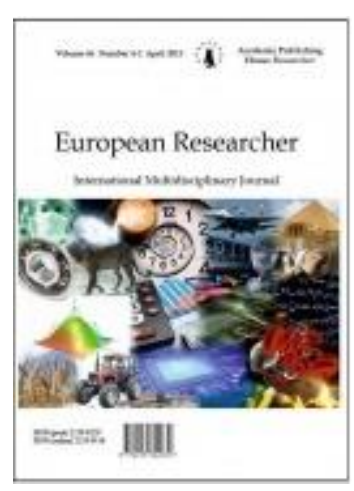

Philological sciences

Филологические науки

UDC 81'1

\title{
The Meta-Language of Advertising in a Synergetic Vision of the World (in English Language)
}

\author{
${ }^{1}$ Aila E. Zhumabekova \\ ${ }^{2}$ Bakhyt M. Toimbaeva \\ 3 Gul'mira M. Baidel'dinova \\ ${ }_{4}^{4}$ Sholpan A. Kakzhanova
}

1-4 Karaganda state technical university - the institution of the First President of Kazakhstan, the Republic of Kazakhstan

Mira Boulevard, 56, Karaganda, Kazakhstan 100027

${ }^{1}$ Master of Philology

E-mail: aila1980@mail.ru

${ }^{2}$ Senior Lecturer

3 Master of Philology

4 Senior Lecturer

\section{Abstract}

The relevance of this article is determined by necessity of consideration of the metalanguage, which is considered a language that expresses the hidden meaning of advertising through natural language, from the point of view of linguistic analysis in the synergy aspect as a main tool used by the metalanguage in the process of representation created in the framework of this direction terminology. The article creates a lexical reservoir used on the respective orientation, which detects the connection with the language phenomena and the facts in our case in advertising. Formed the language of "second order", which is the object of the natural language in all its manifestations. The new synergetic way of thinking in the meta-language of advertising is nonlinear, and evolutionary. This is the current stage of development of linguistics as an attempt of system description meta-language of advertising and its effects on customers are different segments of the population, that is, a synergistic perception of the content of advertising texts in English and their components.

Keywords: meta-language, advertising, synergetic, synergistic vision of the world, advertising in english, manipulation of consciousness, meta-language advertising, advertising via the Internet, advertising in the press, radio advertising, television advertising, outdoor advertising. 


\section{Введение}

Целью этой статьи является выявить и определить понятие метаязыка рекламы на фоне семантико-синтаксических конструкций в синергетическом развитии. Объектом исследования выступает англоязычная реклама, рассматриваемая как синергетическое образование и предметом исследования выступают мета-синергетические принципы смысловой организации англоязычных реклам. Научная новизна заключается в том, что предпринята попытка системного описания метаязыка рекламы и его воздействия на покупателей разных слоев населения, то есть синергетика в содержании рекламных текстов и их компонентов.

\section{Материалы и методы}

Методами, использованными при написании данной статьи, являются сравнительный, сопоставительный, дистрибутивный, трансформационный, компонентный, контекстуальный и статистический анализы, обобщение и систематизация.

\section{Обсуждение}

В рамках данной работы нами были определены сущность метаязыка рекламы в синергетическом видении мира.

Мы рассмотрели метаязык рекламы как самостоятельную дисциплину и выделили основные компоненты, учитывая, что имеется особая структура, основные свойства, классификация и терминологический аппарат.

Мы изучили основные направления исследований метаязыка рекламы в современной лингвистической парадигме. В связи с этим необходимо отметить, что использование метаязыка рекламы крайне важно при передаче прагматического потенциала рекламного текста и необходимо учитывать факторы внутренней и внешней лингвистики, такие как социолингвистические, лингвокультурологические, психолингвистические и т.д. Также необходимо отличать язык, называемый языком-объектом, от языка, на котором ведется исследование языка-объекта и последний называется метаязыком по отношению к данному языку-объекту, это может происходить, в случае, если предметом исследования является естественный или искусственный язык.

Метаязык - это язык, на котором формулируется метатеория. Если не проводить различие между метаязыком и естественным языком, то это может привести к парадоксам. Метаязык должен включать лексику и выражения естественного языка, а также синтаксические и семантические характеристики языка-объекта, соответственно метаязык становится наиболее логически богатым.

Подчеркнем, что сам «рекламный» язык это результат работы специалистов многих отраслей знаний, начиная от филологов и лингвистов до психологов, а метаязык рекламы это язык, который используется в рекламной деятельности для максимальной эффективности манипуляции и воздействия на потребителей.

Таким образом, необходимо еще раз отметить, что:

- метаязык представляет собой знаковую систему, фиксирующую в данный отрезок времени при помощи языковых средств сумму знаний о конкретном языке (языке-объекте);

- сущность метаязыка не отождествляется с понятием научной метаречи, т.е. метаязыкового дискурса, и с понятием метаязыка в теории семантических примитивов в семасиологии;

- основной функцией метаязыка является интерпретация языковых образований, денотатов языка-объекта (фонем, морфем, слов, синтаксических единиц, текста) с помощью специальных средств - метазнаков;

- основное средство, используемое метаязыком в процессе репрезентации, это создаваемая в рамках этой этого направления терминология. Создается лексический пласт, используемый относительно профессиональной ориентированности, который и обнаруживает связь с языковыми явлениями и фактами, в нашем случае в рекламе. Образуется язык "второго порядка", являющийся объектом естественного языка во всех его проявлениях.

Манипуляция сознанием - это действия массовой коммуникации, которые вынуждают адресатов принимать решения не те, что были бы необходимы им самим, а те, что нужны 
организаторам манипуляции. Основная цель метаязыка рекламы в данном случае агрессивное навязывание адресатам товара или услуги при помощи информационного метода, средств массовой коммуникации.

Синергетическое видение мира активно включает в себя использование языкового манипулирования и создает желаемое автором рекламного текста описание действительности.

Использование психологических механизмов это один из способов воздействия рекламного текста, при создании которого используются конструкции, воздействующие на подсознание потребителей и использующие косвенные утверждения.

Созданию синергетического восприятия, в котором потребитель не просто позволит манипулировать собой, а найдет именно для себя желаемый товар или услугу поможет изучение метаязыка как средства манипуляции сознанием. Знание особенностей рекламного текста в целом и использование манипулятивных приемов с лингвистическими средствами при их составлении позволят увеличить эффективность восприятия и понимания рекламного сообщения потребителями.

Языковые средства, при помощи которых автор рекламного текста вызывает интерес потребителя к рекламе, являются основой психологического воздействия при произвольном внимании.

Метаязык рекламы в синергетическом видении мира - это такое восприятие мира, при котором взаимодействие в рекламном тексте позволяет наиболее эффективно добиться поставленной цели, так образуется синергетический эффект, как возникнувшее новое системное свойство при взаимодействии различных, в нашем рассмотрении, лингвистических приемов.

В исследуемых нами рекламных текстах мы обнаружили практически все известные лексические и стилистические средства выражения экспрессивности, удачный подбор и сочетание которых влияет на их эмоциональность и выразительность.

Заголовок, чаще всего встречается в письменных видах рекламы - в прессе и в Интернете. Слоган присутствует в большем количестве в радио и телерекламе. Кроме наружной рекламы основной текст выделяется во всех источниках информации. Эхо-фраза чаще выделяется в устных видах рекламы - на радио и телевидении.

Лексика, обозначающая новые свойства и указывающая на уникальность продукта представлена во всех рекламах, независимо от вида СМИ.

Стилистические приемы практически не используются в Интернет-рекламе, что опять можно объяснить ее лаконичностью, в других видах рекламы они используются почти в одинаковом объеме, но наиболее часто употребляемыми остаются метафоры и эпитеты.

Что касается синтаксических особенностей рекламных текстов, то в рекламных текстах мало используются восклицательные предложения. Императив встречается достаточно часто во всех рекламных текстах на английском языке, что показывает важность побудительной функции рекламы. Вопросительные предложения используются чаще на радио, телевидении и в сети Интернет, чем в только письменных видах рекламы, что, скорее всего, связано с их направленностью на диалогизацию речи, которая лучше происходит при устном произнесении текста.

Мы провели анализ структурных элементов по следующим критериям:

1. - заголовок,

- основной рекламный текст,

- эхо-фраза,

- слоган.

2. Лексические особенности рекламного текста мы разделили на

- специальную лексику, используемую в рекламных текстах,

- стилистические приемы.

3. Синтаксические особенности.

Так, чаще всего в рекламных текстах используется лексика,

- указывающая на уникальность,

- подчеркивающая положительные качества,

- использующая отрицательные конструкции, 
- лексика, которая привлекает внимание к товару или услуге, указывая на новые свойства или черты,

- использующая географические названия мест либо ингредиентов, либо самого товара,

- использующая термины и употребление в рекламе названий авторитетных организаций.

Таким образом, рекламный текст обращен не к эмоциональной, а более к рациональной сфере потребителей. Использование соответствующей лексики создает положительные эмоции, притягательный образ и за счет всего этого и объясняется воздействие на потребителя, тем, что хочется приобрести именно эту продукцию, которая обладает и исключительными свойствами и ожидаемым качеством.

Мы провели анализ 500 единиц рекламных текстов на английском языке, который позволил нам выделить определенные различия. В ходе сравнения мы выявили, что существует ряд лексических, стилистических и синтаксических различий, а также различий по структуре между англоязычными текстами в пределах различных видов средств массовой информации.

Интересно, что, рассмотрев рекламные тексты из прессы, радио, сети Интернет, телевидения и наружной рекламы, мы определяем, что главной стратегией всех рассмотренных нами рекламных текстов является манипулирование, то есть воздействие на потребителя на разных уровнях, в результате этого формируется синергетическое видение мира, в котором основными ценностями являются «успешность» и «нацеленность на положительный результат». Эти положения подтверждены результатами, которые были получены в ходе анализа рекламных текстов. Так на заключительном этапе выделяется синергетика - как язык междисциплинарного общения.

В ходе выполнения исследовательской работы мы изучили 100 рекламных текстов из прессы, 100 рекламных объявлений из сети Интернет, по 100 радио- и телереклам и 100 объявлений наружной рекламы методом сплошной выборки, и, решив поставленные задачи, пришли к следующим выводам:

1. Изучение рекламных текстов представляется актуальным и исследование рекламных текстов массовой информации, в частности, английских рекламных текстов имеет свою традицию.

2. Основное средство, используемое метаязыком в процессе репрезентации, это создаваемая в рамках этого направления терминология. Создается лексический пласт, используемый относительно профессиональной ориентированности, который и обнаруживает связь с языковыми явлениями и фактами, в нашем случае в рекламе. Образуется язык "второго порядка", являющийся объектом естественного языка во всех его проявлениях.

3. Естественный язык и метаязык функционируют в тесной взаимосвязи друг с другом, как бы дополняя друг друга, и оказывая друг на друга определенное воздействие, выражающееся, с одной стороны, в давлении средств языкового описания на языковую систему, а с другой - в необходимости совершенствования метаязыка в связи с постоянным совершенствованием самой языковой системы.

4. Реклама - сложное, многогранное явление, которое исследуется различными научными направлениями и представляет интерес у представителей разных профессий. Выделение различных направлений в исследованиях говорит о развитости рекламы. Сейчас идет речь о том, что рекламист - это не специальность, а указание на то, в какой области человек осуществляет свою профессиональную деятельность. Основной целью рекламы, как и другого вида текста средств массовой информации - это передача информации.

5. Синергетическое видение мира - это главная стратегия всех рассмотренных нами рекламных текстов, в результате которой формируется манипулирование, то есть воздействие на потребителя на разных уровнях, в котором основными ценностями являются «успешность» и «нацеленность на положительный результат». Эти положения подтверждены результатами, которые были получены в ходе анализа рекламных текстов. Так на заключительном этапе выделяется синергетика - как метаязык междисциплинарного общения. 
Для достижения главной цели - выявить и описать семантико-синтаксические и синергетические рекламные образования, мы пришли к общему выводу:

- метаязык рекламы - динамично развивающийся семантико-грамматический пласт, формирующийся на основе профессиональной ориентированности рекламы и характеризующийся рядом понятийных и стилистических особенностей;

- метаязык рекламы - это язык, который широко используется в рекламной деятельности для максимальной эффективности манипуляции и воздействия на потребителей;

- эффективность воздействия рекламных текстов достигается использованием психологических и лингвистических приемов естественного языка и во многом определяется характером воздействия различных составляющих.

- синергетическое видение мира потребителя играет важную роль при создании рекламного текста, что определяет его реакцию на использование метаязыка рекламы, который, в свою очередь и находит своего потребителя через различные источники массмедиа.

\section{Заключение}

В последнее время с развитием междисциплинарных исследований, глобализацией и компьютеризацией стало возможным получение и обмен информацией в рамках различных научных исследований, в том числе и по лингвистике.

«Рекламный» язык это результат работы специалистов многих отраслей знаний, начиная от филологов и лингвистов, заканчивая копирайтерами и психологами, а метаязык рекламы это язык, который используется в рекламной деятельности для максимальной эффективности манипуляции и воздействия на потребителей.

\section{Литература}

1. Дейян Арманд. Реклама / Пер. с фр. В. Мазю; Общ. ред. В.С. Загашвили. 5-е изд., испр.: Прогресс, 1993. 175 с. (Деловая Франция).

2. Х Хакен Г. Синергетика. М.: Мир, 1980. 405 с.

3. Добросклонская Т.Г. Медиалингвистика: системный подход к изучению языка СМИ. М.: Флинта, Наука, 2008, с. 142.

4. Барт Р. Литература и метаязык // Барт Р. Избранные работы. Семиотика. Поэтика. М.: Прогресс, 1994. С.131-132.

5. Закон Республики Казахстан «О рекламе» от 19 декабря 2003 года № 508-II

6. Aleksandra A. Vorozhbitova, Gaukhar I. Issina. Professional Linguistic Personality as Subject of Discursive Processes: Conception of Linguistic Rhetorical Culturological Education // European Journal of Social and Human Sciences, 2014, Vol.(1), № 1, pp. 44-55.

7. Aleksandra A. Vorozhbitova, Marina M. Mishina. Sergey I. Potapenko. Free Verse as Active Discursive Process of Literary Belletristic Communication: Linguistic \& Rhetorical Approach // European Journal of Social and Human Sciences, 2014, Vol.(1), № 1, pp. 56-6o.

\section{References}

1. Deiyan Armand. Reklama / Per. s fr. V. Mazyu; Obshch. Red V.S. Zagashvili. 5-e izd., ispr.: Progress, 1993. 175 s. (Delovaya Frantsiya).

2. Khaken G. Sinergetika. M.: Mir, 1980. 405 s.

3. Dobrosklonskaya T.G. Medialingvistika: sistemnyi podkhod k izucheniyu yazyka SMI. M.: Flinta, Nauka, 2008, 142 s.

4. Bart R. Literatura i metayazyk // Bart R. Izbrannye raboty. Semiotika. Poetika. M.: Progress, 1994. S.131-132.

5. Zakon Respubliki Kazakhstan «O reklame» ot 19 dekabrya 2003 goda № 508-II.

6. Aleksandra A. Vorozhbitova, Gaukhar I. Issina. Professional Linguistic Personality as Subject of Discursive Processes: Conception of Linguistic Rhetorical Culturological Education // European Journal of Social and Human Sciences, 2014, Vol.(1), № 1, pp. 44-55

7. Aleksandra A. Vorozhbitova, Marina M. Mishina. Sergey I. Potapenko. Free Verse as Active Discursive Process of Literary Belletristic Communication: Linguistic \& Rhetorical Approach // European Journal of Social and Human Sciences, 2014, Vol.(1), № 1, pp. 56-60. 
УДК 81 '1

\title{
Метаязык рекламы в синергетическом видении мира (на материале английского языка)
}

\author{
${ }^{1}$ Айла Ермековна Жумабекова \\ 2 Бахыт Мухамедиевна Тоимбаева \\ 3 Гульмира Муратовна Байдельдинова \\ 4 Шолпан Айдархановна Какжанова
}

1-4 Карагандинский государственный технический университет - вуз Первого Президента РК,
Республика Казахстан
Бульвар Мира, 56, город Караганда, Казахстан 100027
1 Магистр филологии
E-mail: aila1980@mail.ru
² Старший преподаватель
3 Магистр филологии
4 Старший преподаватель

Аннотация. Актуальность данной статьи определяется необходимостью рассмотрения метаязыка, считающимся языком, выражающим «скрытый» смысл рекламы через естественный язык, с точки зрения лингвистического анализа в синергетическом аспекте, как основное средство, используемое метаязыком в процессе репрезентации и создаваемая в рамках этого направления терминология. Создается лексический пласт, используемый относительно соответствующей ориентированности, который и обнаруживает связь с языковыми явлениями и фактами, в нашем случае в рекламе. Образуется язык "второго порядка", являющийся объектом естественного языка во всех его проявлениях. Новый синергетический стиль мышления в метаязыке рекламы является нелинейным, эволюционным. Это современный этап развития лингвистики, так как предпринята попытка системного описания метаязыка рекламы и его воздействия на покупателей разных слоев населения, то есть синергетическое восприятие содержания рекламных текстов на английском языке и их компонентов.

Ключевые слова: метаязык, реклама, синергетика, синергетическое видение мира, реклама на английском языке, манипуляция сознанием, метаязык рекламы, реклама из сети Интернет, реклама из прессы, реклама на радио, реклама на телевидении, наружная реклама. 